\title{
Maxillary Adenomatoid Odontogenic Tumor with Retention of Two Permanent Teeth: An Unusual Association
}

Norith de Jesus Recendez Santillan¹, Víctor Hiram Barajas Perez¹, Alfredo Salinas Noyola1, Giulio Fortuna ${ }^{2,3 \S}$, and Julio C. Salas-Alanís ${ }^{1,3,4 \S^{*}}$

Received: 28 January 2016; Returned for revision: 01 March 2016; Received in revised form: 19 June 2016; Accepted: 27 June 2016; Published online: 16 July 2016

(C) The author(s) 2016. Published with open access at www.uscip.us

\section{Dear Editor,}

Adenomatoid odontogenic tumor (AOT) is a benign non-aggressive lesion with slow but progressive growth and no tendency of recurrence, arising from odontogenic epithelium of the enamel organ and representing about 1 to $9 \%$ of all odontogenic tumors (Lee and Kim, 2013). The age ranges between 3 and 82 year of age and in more than $80 \%$ of cases it affects young people between 10-29 years old, with a female-male ratio of 1.9:1 (Philipsen and Reichart, 2007).

We report a case of 15-year-old Mexican female patient with a chief complaint of 2 missed permanent teeth in the right anterior maxillary region. Extra-oral examination showed no remarkable findings, whereas an intra-oral examination exhibited an asymptomatic class III molar occlusion and absence of maxillary right lateral incisor and canine with a deviated midline, without any swelling in the gingival fornix (Fig. 1A). No lesions in oral-pharyngeal soft tissues were detected. The patient was otherwise healthy with no systemic disease and denied taking any medications at the time of visit, as well as smoking or drinking habits.

A cone beam computed tomography exam of maxillary region showed a hyperdense lesion

*Corresponding e-mail: drjuliosalas@gmail.com

1 Departament of Dentistry, Universidad de Monterrey, Avenida Morones Prieto 4500 Pte. Colonia Jesus M. Garza, San Pedro Garza García. CP 66238

2 Department of Diagnostic Sciences, Louisiana State University School of Dentistry, 1100 Florida Ave, New Orleans, LA, 70119, USA

3 D.eb.RA. Mexico Foundation, Otomí \#211, casi esq. P. Elías Calles Colonia Azteca, Guadalupe N.L., 67150, Monterrey, Nuevo Leon, Mexico

4 Department of Basic Science, Universidad de Monterrey, Avenida Morones Prieto 4500 Pte. Colonia Jesus M. Garza, San Pedro Garza Garcia. CP 66238

$\S$ These two authors equally contributed to manuscript and need to be considered as last author. 
Norith de Jesus Recendez Santillan, Víctor Hiram Barajas Perez, Alfredo Salinas Noyola, Giulio Fortuna, and Julio C. Salas-Alanís / American Journal of Oral Medicine (2016) Vol. 2 No. 1 pp. 21-25

surrounded by a hypodense region, located between the crown of the right impacted canine and the right upper impacted lateral incisor. The tumor measured 13.2 × 14.4 x $19.5 \mathrm{~mm}$ showing no signs of cortical erosion and was located adjacent to the anterior wall of the right maxillary sinus and nasal lateral wall (Fig. 1B).

An excisional biopsy of the lesion was performed (Fig. 1C) and the histopathological evaluation revealed an island of duct-like pattern of cuboidal ephitelial cells, the nuclei of which are polarized away from the central lumen surrounded with conective tissue stroma (Fig.1D).
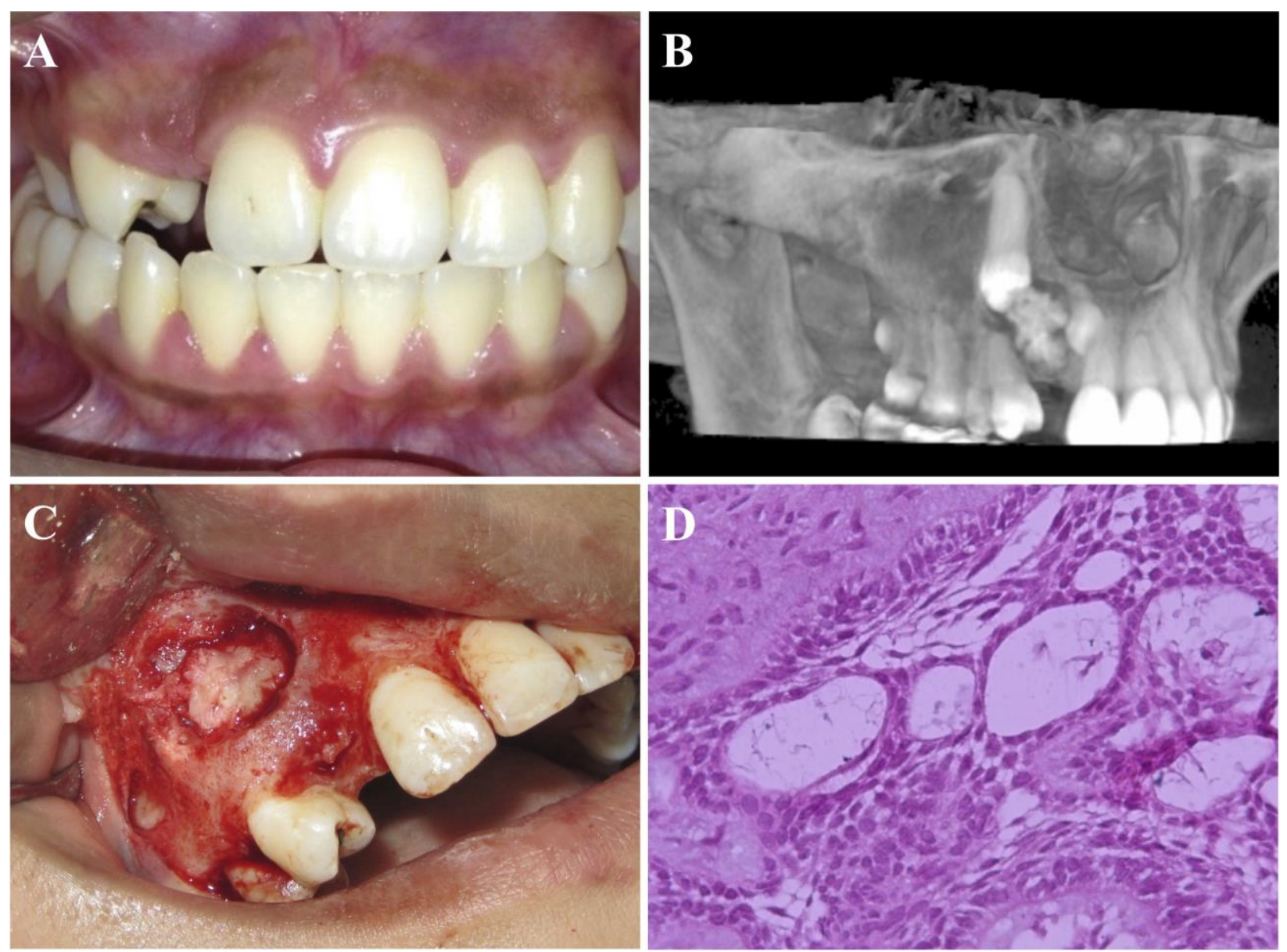

Fig. 1. A) Absence of right maxillary lateral incisor and canine and right deviation of mid-line; B) Three-dimensional reconstruction of maxillary right region shows a well defined hyperdense image located between the crown of the right upper impacted canine, surrounded by hypodense halo, and the right lateral impacted incisor; C) Surgical access with exposure of the lesion before its complete excision; D) Histopathological examination exhibits odontogenic epithelial cells islands forming tubular structures in a scant connective tissue stroma. The duct-like structure is lined by a single row of cuboidal epithelial cells, whose nuclei are polarized away from the central lumen, and contain amorphous eosinophilic material (H\&E 40x). 
Norith de Jesus Recendez Santillan, Víctor Hiram Barajas Perez, Alfredo Salinas Noyola, Giulio Fortuna, and Julio C. Salas-Alanís / American Journal of Oral Medicine (2016) Vol. 2 No. 1 pp. 21-25

The entire lesion was enucleated along with a removal of the right impacted maxillary canine due to its malposition and poor prognosis in the reinstatement on the dental arch. Conversely, the right upper impacted lateral incisor was preserved for an orthodontic repositioning. Patient was discharged with domiciliary therapy of amoxicillin/clavulanate $875 / 125 \mathrm{mg}$ every 12 hours for 8 days and analgesic therapy with ketorolac $10 \mathrm{mg} 1$ tablet every 8 hours for 5 days.

At 4 months of follow-up, a complete healing of surgical site was obtained (Fig. 2A) and a panoramic radiograph showed an almost complete resolution of the void left after surgery and orthodontically slow reposition of the right upper lateral incisor (Fig. 2B).

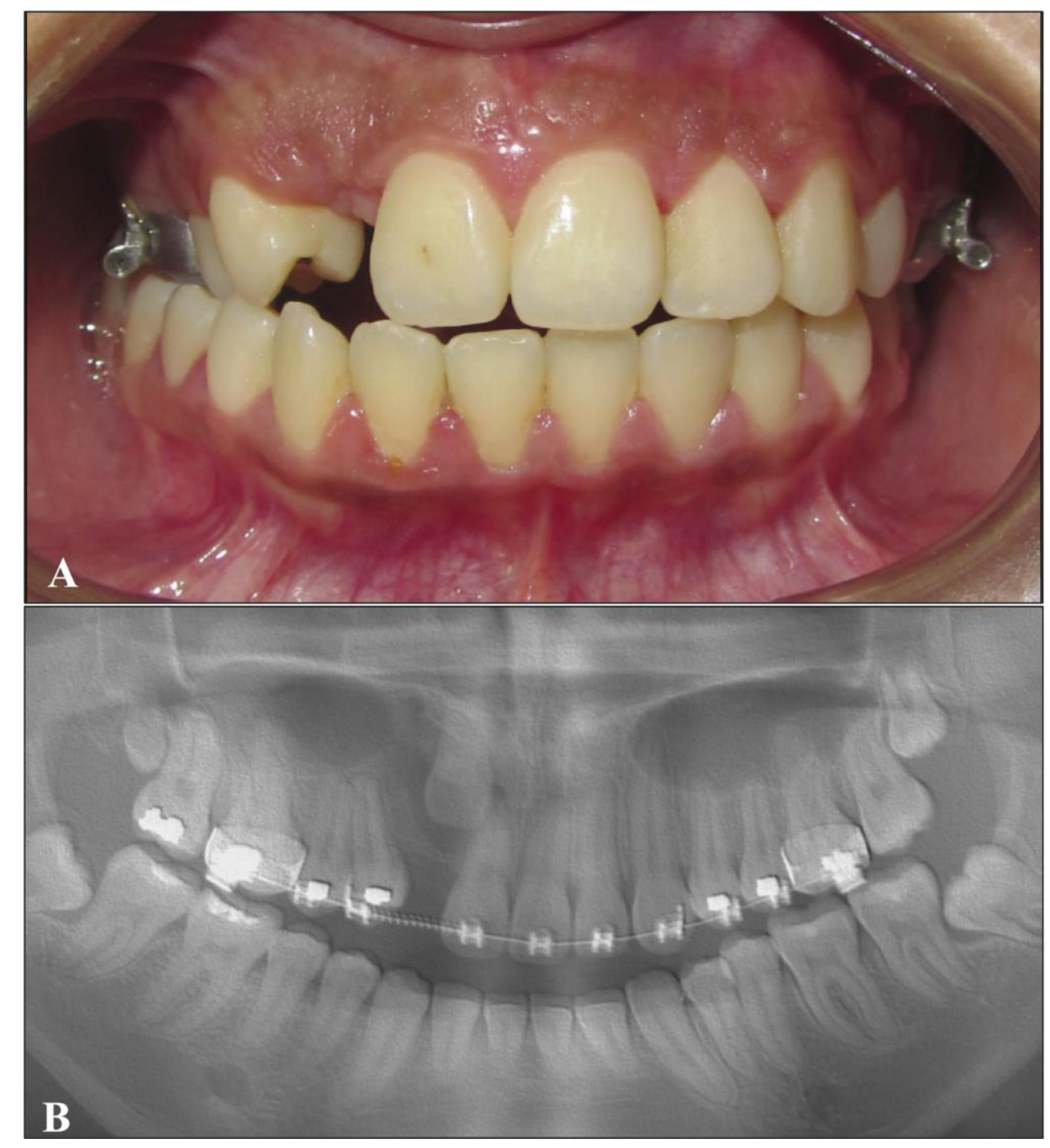

Fig. 2. A) Four months postoperative intraoral image; B) Panoramic radiograph view shows maxillary alveolar bone with no signs of lesion. 
Norith de Jesus Recendez Santillan, Víctor Hiram Barajas Perez, Alfredo Salinas Noyola, Giulio Fortuna, and Julio C. Salas-Alanís / American Journal of Oral Medicine (2016) Vol. 2 No. 1 pp. 21-25

AOT has three clinico-topographic variants: 1) follicular, 2) extrafollicular and 3) peripheral (Philipsen and Reichart, 1999). The most frequent variant is the follicular intraosseous one (71\%), which is usually related to an unerupted permanent tooth, whereas the extrafollicular variant may occur in the radicular/periapical region, in the intera-radicular region or in a region not adjacent to any tooth (Philipsen and Reichart, 1999) and can be rarely associated with an ameloblastoma or preexisting odontogenic cystic lesions (Jivan et al, 2007). The peripheral variant is the less frequent (4.4\%) (Philipsen and Reichart, 1999) and is usually observed as an expanding gingival lesion affecting the fornix and the alveolar ridge (Prasad et al, 2011).

Clinically, AOT is usually asymptomatic and characterized by the absence of a permanent tooth in the dental arch, and a variable increase in volume in the affected region, that can even destroy adjacent structures (Dhupar et al, 2016). Radiographically most AOTs appear as unilocular images with smooth borders, that surround greater portions of the impacted teeth, usually displacing (75\%) and rarely resorbing roots (12.5\%) (Chindasombatjaroen et al, 2012). Such lesions may extend apically beyond the cement-enamel junctions or enclose the entire teeth, exhibiting either a radiolucent picture with no calcification (50\%) numerous radiopaque foci either dispersed or clustered in the radiolucency (50\%) (Chindasombatjaroen et al, 2012).

Differential diagnosis may include other cystic lesions and tumors of the jaw region, such as ameloblastoma, dentigerous cyst, calcifying odontogenic cyst and odontoma (Rick, 2004). Due to its benign biological behavior with slow growth and rare recurrence, the first line of treatment includes conservative surgical enucleation or curettage (Philipsen and Reichart, 1999).

Histologically, AOT is characterized by solid nodules of lineal cuboidal o columnar cells surrounded minimal stroma, in the spaces between the epithelial nodules has a spindle-shaped or polygonal cells, whereas in the cellular areas a tubular or duct-like structures forming lumens that can be empty or filled with hyaline eosinophilic material or cellular debris (Philipsen and Reichart, 1999).

The odontogenic adenomatoid tumor is mainly localized in the maxilla with $64.3 \%$ of cases reported versus $37.5 \%$ in the mandibule (Philipsen and Reichart, 2007). It is frequently associated with an impacted tooth, mainly canine, described in more than $60 \%$ of cases (Lee and Kim, 2013), and, very rarely, with third molars reported in only $2.8 \%$ of cases (Philipsen and Reichart, 2007). Similarly, multiple inclusions of permanent teeth seem to be quite rare and have been reported only in the mandible (More et al, 2013; Jain and Oswal, 2014; Sharma et al, 2012). Therefore, this case appears unique as it describes for the first time a maxillary case of AOT associated with two impacted teeth.

It is important for oral medicine specialists and general dentists to examine patients in the absence of more than one tooth in the maxilla as well as in the mandible, with imaging support study and histopathologic evaluation. Both of them are vital in order to establish an early diagnosis and, subsequently, the most appropriate treatment plan. The aim is to avoid an excessive bone loss and possibly preserve the involved impacted teeth in order to orthodontically restore patient's natural dentition and occlusion. 
Norith de Jesus Recendez Santillan, Víctor Hiram Barajas Perez, Alfredo Salinas Noyola, Giulio Fortuna, and Julio C. Salas-Alanís / American Journal of Oral Medicine (2016) Vol. 2 No. 1 pp. 21-25

\section{Acknowledgements}

None

\section{Conflict of Interest}

None

\section{Funding}

None

\section{References}

Chindasombatjaroen, J., Poomsawat, S. \& Klongnoi, B. (2012). Calcifying cystic odontogenic tumor associated with other lesions: case report with cone-beam computed tomography findings. Oral Surg Oral Med Oral Pathol Oral Radiol, 113 (3), 414-420.

http://dx.doi.org/10.1016/i.0000.2011.09.009

Dhupar, V., Akkara, F. \& Khandelwal, P. (2016). An unusually large aggressive adenomatoid odontogenic tumor of maxilla involving the third molar: A clinical case report. Eur J Dent, 10 (2), 277-280. http://dx.doi.org/10.4103/1305-7456.178308

Jain, M.K. and Oswal, S. (2014). Adenomatoid Odontogenic Tumor of Mandible - 'Master of Disguise'. J Dent App, 1(3), 40-42.

Jivan, V., Altini, M., Meer, S. \& Mahomed, F. (2007). Adenomatoid odontogenic tumor (AOT) originating in a unicystic ameloblastoma: a case report. Head Neck Pathol, 1 (2), 146-149. http://dx.doi.org/10.1007/s12105-007-0005-6

Lee, S. K. \& Kim, Y. S. (2013). Current concepts and occurrence of epithelial odontogenic tumors: I. Ameloblastoma and adenomatoid odontogenic tumor. Korean J Pathol, 47 (3), 191-202. http://dx.doi.org/10.4132/KoreanJPathol.2013.47.3.191

More, C. B., Das, S., Gupta, S. \& Bhavsar, K. (2013). Mandibular adenomatoid odontogenic tumor: Radiographic and pathologic correlation. J Nat Sci Biol Med, 4 (2), 457-462. http://dx.doi.org/10.4103/0976-9668.116965

Philipsen, H. P. \& Reichart, P. A. (1999). Adenomatoid odontogenic tumour: facts and figures. Oral Oncol, 35 (2), 125-131. http://dx.doi.org/S1368-8375(98)00111-0

Philipsen, H. P., Reichart, P. A., Siar, C. H., Ng, K. H., Lau, S. H., Zhang, X., . . Adebayo, E. T. (2007). An updated clinical and epidemiological profile of the adenomatoid odontogenic tumour: a collaborative retrospective study. J Oral Pathol Med, 36 (7), 383-393. http://dx.doi.org/JOP536

Prasad, G., Nair, P., Thomas, S., Gharote, H., Singh, N. \& Bhambal, A. (2011). Extrafollicular adenomatoid odontogenic tumour. BMJ Case Rep, 2011 http://dx.doi.org/10.1136/bcr.03.2011.3963

Rick, G. M. (2004). Adenomatoid odontogenic tumor. Oral Maxillofac Surg Clin North Am, 16 (3), 333-354. http://dx.doi.org/S1042-3699(04)00045-7

Sharma, N., Passi, S., and Kumar, V.V. (2012) Adenomatoid odontogenic tumor: As an unusual mandibular manifestation. Contemp Clin Dent, 3(Suppl1), S29-S32. 